\title{
The spindle of oocytes observed by polarized light microscope can predict embryo quality
}

\author{
Tung T. Nguyen, Hang T. Doan*, Lam H. Quan
}

Department of In-Vitro Fertilization, Military Institute of Clinical Embryology and Histology, Military Medical University, Hanoi, Vietnam

Received: 22 October 2018

Accepted: 28 November 2018

*Correspondence:

Dr. Hang T. Doan,

E-mail: hangdt166@gmail.com

Copyright: () the author(s), publisher and licensee Medip Academy. This is an open-access article distributed under the terms of the Creative Commons Attribution Non-Commercial License, which permits unrestricted non-commercial use, distribution, and reproduction in any medium, provided the original work is properly cited.

\begin{abstract}
Background: The aim is to evaluate spindle position of metaphase II oocyte and the development of embryos originated from oocytes with spindle and without spindle.

Methods: Cross-sectional analysis Research: 250 MII oocytes were analyzed with polarized microscope in Military Institute of Clinical Embryology and Histology, Vietnam Military Medical University.

Results: Spindles were detected in 170 (77.98\%) of 218 metaphase II oocytes, 115 spindles (67.65\%) of MII oocytes is beneath or adjacent to the first polar body, 55 oocytes had the spindle located between 300 and 1800 away from the first polar body. Fertilization rate and the rate of good quality embryos in oocytes with a visible spindle (77.98\% and $61.02 \%)$ were higher than those in oocytes without a visible spindle $(22.02 \%$ and $36.84 \%)$, the difference was statistically significant with $\mathrm{p}<0.001$ and $\mathrm{p}<0.05$.

Conclusions: The spindle position of metaphase II oocytes is not always beneath or adjacent to the first polar body. Fertilization rate and the rate of good quality embryos in oocytes with a visible spindle were higher than those in oocytes without a visible spindle.
\end{abstract}

Keywords: ICSI (intracytoplasmic sperm injection), Metaphase II oocyte, Polscope, Spindle

\section{INTRODUCTION}

Identifying whether an oocyte in metaphase II (MII) arrest or in the early phases of activation would be valuable for IVF, intracytoplasmic sperm injection (ICSI), and cloning, because preactivated oocytes cannot be fertilized normally. ${ }^{1,2}$ In addition, spindle dynamics during the initial phases of activation in living oocytes could provide a new marker for embryo quality.

Besides inducing biochemical alteration, oocyte activation is associated with several morphologic changes, including cortical granule exocytosis, reorganization of the fine structure of the zona pellucida, extrusion of the second polar body, and pronuclear formation. ${ }^{1-3}$ However, most of these morphological changes are difficult to observe without fixation, immunostaining, and fluorescence microscopy. Spindle movements or subtle changes in the meiotic spindle occurring in living oocytes might not be observed by the light microscopy.

A method for identifying whether an oocyte is in MII arrest or transition to anaphase or telophase II would allow for prompt decisions regarding whether artificial activation of oocytes would be required after ICSI.

Failure of oocyte activation has been one of the main causes of fertilization failure after ICSI, and subsequent or combined activation treatment has improved fertilization. ${ }^{4,5}$

Moreover, the abnormal genetic oocytes are made by ovarian stimulation with impossibility in passing the 
physical limitation that can cause failure of embryos development inside uterus. Oocyte selection with best quality without genetic abnormalities by non-invasive technique is essential.

Polarized light microscopy images birefringence, an optical property that result from molecular order and allows visualization of highly orderal biological structures such as spindles. ${ }^{6-9}$

Polarized light microscope allows embryologist to obverse morphology of the spindle. The appearance of spindle helps us recognize either oocyte maturation or the quality of laboratory.

There are two goals in this research:

- Evaluation of spindle location of mature oocytes

- Evaluation of embryos development by oocytes with spindle and oocytes with not-observed spindle.

\section{METHODS}

\section{Clinical samples}

During the period covering January to March 2018, mature oocytes of IVF patient at Military Institute of Clinical Embryology and Histology, Military Medical University, Hanoi, Vietnam.

Selection criteria: patients under 35 years old, $3 \mathrm{ng} / \mathrm{ml}<$ $\mathrm{AMH}<10 \mathrm{ng} / \mathrm{ml}$, the number of secondary follicles of 5 15 on the second or third day of menses cycle; the absence of polycystic ovaries, low response to ovary stimulation, low quantity and quality sperm.

\section{Equipments and materials}

POLARIZED LIGHT MICROSCOPE Ti-U Nikon TE2000 with Module polarAIDE - Octax laser system, Digital Camera. Cultural media of Vitrolife (Sweden). Bench top incubators (Cook)

\section{Methods}

Cross-sectional analysis Research

\section{Oocyte preparation}

The controlled ovarian stimulation, following the GnRH antagonist protocol. Ovary was under ultrasound daily until having at least 3 follicles bigger than $17 \mathrm{~mm}$. Ovulation was triggered by hCG (human Chorionic Gonadotropin) 5000IU injection.

Retrieve Oocytes after injection hCG 35-36h. After retrieving, put oocytes in incubator at $37 \mathrm{oC}, 5 \% \mathrm{CO} 2$ for 2 hours.
Then denude Oocytes by enzyme hyaluronidase, put fresh Oocytes in incubator for 1 hour. Evaluate maturation level of oocytes and spindle before ICSI.

\section{Cultures}

After ICSI 16-18h, put zygote into new medium (G1 plus). Evaluate Embryos in the second day, and then put them into G2 plus in Incubator Cook Classify Embryos in the third day basing on criteria of Alpha of ESHRE $2011^{10}$

\section{RESULTS}

Following table 1 in 218 matured oocytes, there are 170 visible spindle oocytes $(77,98 \%)$ and 48 not observed spindle oocytes $(22,02 \%)$.

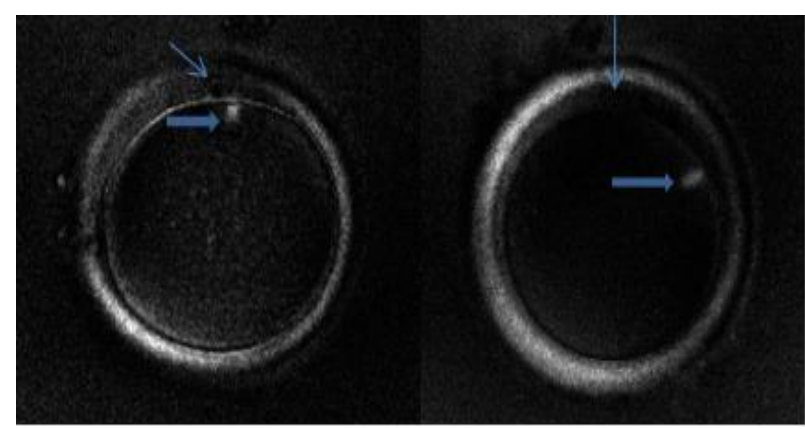

Figure 1: MII observed by polarized microscope, with magnification $\times 200$

The result of table 2 showed that of 170 visible spindle matured oocytes, there were 115 oocytes $(67,65 \%)$ with spindle directly beneath and adjacent to the first polar body, 40 oocytes $(23,53 \%)$ with spindle located between 30 and 60 degrees away from the first polar body, 10 oocytes $(5,88 \%)$ with spindle located between 60 and 120 degrees angle, 5 oocytes $(2,94 \%)$ with spindle located between 120 and 180 degrees angle. (The thin arrow: the first polar body.

The bold arrow: meiosis spindle, beneath the first polar body, the right image shows that the spindle located in 70 degrees way from the first polar body).

The fertilization rate of Mature oocytes with visible spindle was $69,41 \%$, whereas this of mature oocytes with not-observed spindle was $39,58 \%$. The difference was statistically significant with $\mathrm{p}<0,001$.

Table 1: The rate of visible spindle in the mature oocytes.

\begin{tabular}{|l|l|l|}
\hline MIII & $\begin{array}{l}\text { MII with visible } \\
\text { spindle }\end{array}$ & $\begin{array}{l}\text { MII not observed } \\
\text { spindle }\end{array}$ \\
\hline 218 & 170 & 48 \\
$(100 \%)$ & $(77,98 \%)$ & $(22,02 \%)$ \\
\hline
\end{tabular}


Table 2: Spindle location.

\begin{tabular}{|c|c|c|c|c|}
\hline $\begin{array}{l}\text { MII with visible } \\
\text { spindle }\end{array}$ & $\begin{array}{l}\text { Directly beneath and adjacent to the first polar } \\
\text { body }\end{array}$ & 30-60 degrees & 60-120 degrees & 120-180 degrees \\
\hline $170(100 \%)$ & $115(67.65 \%)$ & $40(23.53 \%)$ & $10(5.88 \%)$ & $5(2.94 \%)$ \\
\hline
\end{tabular}

The rate of good embryos among MII oocytes with visible spindle was higher than that among MII oocytes with not-observed spindle $(61,02 \%$ and $36,84 \%)$. The difference was statistically significant with $\mathrm{p}<0,05$ (table $3)$.

Table 3. The preclinical characteristics.

\begin{tabular}{|l|l|l|l|}
\hline Classification & MII oocytes with visible spindle & MII oocytes not observed spindle & p \\
\hline The fertilization rate & $69.41 \%(118 / 170)$ & $39.58 \%(19 / 48)$ & $<0.001$ \\
\hline Embryo classification & & & $<0.05$ \\
\hline Good & $61.02 \%(72 / 118)$ & $36.84 \%(7 / 19)$ & $>0.05$ \\
\hline Fair & $27.12 \%(32 / 118)$ & $47.37 \%(9 / 19)$ & $>0.05$ \\
\hline Bad & $11.86 \%(14 / 118)$ & $15.79 \%(3 / 19)$ & \\
\hline
\end{tabular}

\section{DISCUSSION}

In this research, oocytes were observed at 39 hours after hCG administration, which is the time that Cohen et. al. 2004 had observed the spindle of MII oocytes with the highest rate $(81.5 \%) .{ }^{11}$

In this research, in spite of 48 oocytes with the first polar body, the rate of invisible spindle oocytes was $22,02 \%$. To explain the absence spindle in MII oocytes, Montag et Al using time-lapse to observe the oocyte maturation in the in-vitro showed that when MI oocytes extruded the first polar body, a spindle had established the bridge between the polar body and the oolemma for 75-90 minutes. These imagine was recorded at Telophase 1 by polarized microscope. After extruding the first polar body, it took 115-150 minutes to establish the spindle beneath the first polar body. Therefore, the spindle absence was in the oocyte meosis. ${ }^{12}$

In ICSI, the spindle location of mature oocyte was involved to the first polar body. The ICSI micropipette had to avoid the spindle in the injection. However, several researches reported that the first polar body did not exactly predict the spindle location. ${ }^{13}$ Thus the spindle could be injured when located far from the first polar body.

The use of polarized microscope could reduce spindle injured in ICSI. In this research, there were 8 oocytes $(8,7 \%)$ with spindle located between 600 and 1200 degrees away the first polar body, this location was for injecting by the ICSI micropipette though out the 3 -hour position in the oocyte. To explain the change of spindle location away from the first polar body, in the oocyte denudation by physical processing, the first polar body was moved. Another reason was that the fluid surrounds the spindle forced its movement. ${ }^{14}$

Oocyte assessment by using polarization microscope improved the prediction of oocyte quality. In the Woodward's research 2008, the fertilization rate and embryo quality in day 3 and day 5 of the oocyte MII with visible spindle were higher and better than those of the oocyte MII with not-observed spindle. ${ }^{15}$ In our research, fertilization rates between two groups were different significantly statistically ( $p<0,001$ ). This result is similar to the result of Cohen et al, Heindryckx..$^{11,16}$

There are many reasons for the IVF failure, in which the major reason is from chromosome abnormalities and $80 \%$ of aneuploidy embryos are from the oocyte meiosis $1 .{ }^{17}$ Chromosome dividing errors often happen in meiosis 1 . The main mechanism is the error in homologous chromosome pairing in Prophase 1, recombination and early dividing of chromosome. Spindle controls the chromosome movement though many periods in meiosis and has a crucial role of meiosis. ${ }^{11}$

According to Moon et. al. 2003 implemented in 626 MII oocyte, the rate of good embryos among MII oocytes with visible spindle $64,2 \%$ was higher than that among MII oocytes with not-observed spindle 35,9\% ( $\mathrm{p}<0,01)$, and the rate of multi-pronuclear in MII oocytes with visible spindle (3PN, 4PN) was reduced, compared to MII oocytes with not-observed spindle $(5,9 \%$ and $10,7 \%) .{ }^{14}$

\section{CONCLUSION}

The spindle location may be far away from the first polar body. The fertilization and good embryo rates of MII 
oocytes with visible spindle were higher than those of MII oocytes with not-observed spindle.

\section{ACKNOWLEDGMENTS}

Authors would like to thank Military Institute of Clinical Embryology and Histology, Military Medical University for their support during study, and to the patients for their voluntary participation in this research.

\section{Funding: No funding sources}

Conflict of interest: None declared

Ethical approval: The study was approved by the Institutional Ethics Committee

\section{REFERENCES}

1. Wang WH, Abeydeera LR, Prather RS, Day BN. Functional analysis of activation of porcine oocytes by spermatozoa, calcium ionophore, and electrical pulse. Molecular Reproduction and Develop: Incorp Gamete Res. 1998;51(3):346-53.

2. Wang WH, Machaty Z, Abeydeera LR, Prather RS, Day BN. Time course of cortical and zona reactions of pig oocytes upon intracellular calcium increase induced by thimerosal. Zygote;1999;7(1):79-86.

3. Schultz RM, Kopf GS. Molecular basis of mammalian egg activation. Curr Top Dev Biol. 1995;30:21-62.

4. Yanagida K, Katayose H, Yazawa H, Kimura Y, Sato A, Yanagimachi H, et al. Successful fertilization and pregnancy following ICSI and electrical activation. Hum Reprod. 1999;14(5):1307-11.

5. Terasik J Sousa M. More than $90 \%$ fertilization rates after intracyto plasmic sperm injection and artificial induction of oocyte activation with calcium ionophore. Fertil Sterile. 1995;63(2):343-9.

6. Liu L, Trimarchi JR, Oldenbourg R, Keefe DL. Increased birefringence in meiotic spindle provides a new marker for the onset of activation in living oocytes. Biol Reprod. 2000;63(1):251-8.

7. Liu L, Oldenbourg R, Trimarchi JR, Keefe DL. A reliable, noninvasive technique for spindle imaging and enucleation of mammalian oocytes. Nat Biotechnol. 2000;18(2):223-5.

8. Liu L, Trimarchi JR, Keefe DL. Haploidy but not parthenogenetic activation leads to increased of apotosis in mouse embryos. Biol Reprod. 2000;66(1):204-10.

9. Liu L, Keefe DL. Ageing-associated aberration in meiosis of oocytes from senescence-accelerated mice. Human Reproduct. 2002;17(10):2678-85.

10. "The Istanbul consensus workshop on embryo assessment: proceedings of an expert meeting." Human Reproduction. 2011;26(6):1270-83.

11. Cohen Y, Malcov M, Schwartz T, Mey-Raz N, Carmon A, Cohen T, Lessing JB, Amit A, Azem F. Spindle imaging: a new marker for optimal timing of ICSI?. Human Reproduct. 2004;19(3):649-54..

12. Montag M, Schimming t, van der Ven H. Spindle imaging in human oocyte the impact of the meiotic cell cycle. Repro Biomed Online. 2006;12(4):442446.

13. Silva CP, Kommineni K, Oldenbourg R, Keefe DL. The first polar body does not predict accurately the location of the metaphase II meiotic spindle in mammalian oocytes. Fertil Steril. 1999;71(4):719-21.

14. Moon JH, Hyun CS, Lee SW, Son WY, Yoon SH, Lim JH. Visualization of the metaphase II meiotic spindle in living human oocytes using the Polscope enables the prediction of embryonic developmental competence after ICSI. Human Reproduct. 2003;18(4):817-20.

15. Woodward BJ, Montgomery SJ, Hartshorne GM, Campbell KH, Kennedy R. Spindle position assessment prior to ICSI does not benefit fertilization or early embryo quality. Reproduct Biomed online. 2008;16(2):232-8.

16. Heindryckx B, De Gheselle ST, Lierman S, Gerris J, De Sutter P. Efficiency of polarized microscopy as a predictive tool for human oocyte quality. Human Reproduct. 2011;26(3):535-44.

17. Hassold T, Hunt P. To err (meiotically) is human: the genesis of human aneuploidy. Nature Reviews Genetic. 2001;2(4):280.

Cite this article as: Nguyen TT, Doan HT, Quan LH. The spindle of oocytes observed by polarized light microscope can predict embryo quality. Int $\mathbf{J}$ Reprod Contracept Obstet Gynecol 2019;8:131-4. 